Research Article

\title{
Metabarcoding Analysis of Bacterial Communities Associated with Media Grow Bed Zones in an Aquaponic System
}

\author{
Nasser Kasozi, ${ }^{1,2}$ Horst Kaiser, ${ }^{3}$ and Brendan Wilhelmi $\mathbb{i D}^{1}$ \\ ${ }^{1}$ Department of Biochemistry and Microbiology, Rhodes University, P.O. Box 94, Grahamstown 6140, South Africa \\ ${ }^{2}$ Animal Resources Research Programme, Abi Zonal Agricultural Research and Development Institute, \\ National Agricultural Research Organisation, P.O. Box 219, Arua, Uganda \\ ${ }^{3}$ Department of Ichthyology and Fisheries Science, Rhodes University, P.O. Box 94, Grahamstown 6140, South Africa \\ Correspondence should be addressed to Brendan Wilhelmi; b.wilhelmi@ru.ac.za
}

Received 30 June 2020; Accepted 21 September 2020; Published 1 October 2020

Academic Editor: Shady Amin

Copyright (C) 2020 Nasser Kasozi et al. This is an open access article distributed under the Creative Commons Attribution License, which permits unrestricted use, distribution, and reproduction in any medium, provided the original work is properly cited.

\begin{abstract}
The development of environmentally sustainable plant and fish production in aquaponic systems requires a complete understanding of the systems' biological components. In order to better understand the role of microorganisms in this association, we studied the bacterial communities in the dry, root, and mineralized zones of a flood-and-drain media bed aquaponic system. Bacterial communities were characterized using metabarcoding of the V3-V4 16S rRNA regions obtained from paired-end Illumina MiSeq reads. Proteobacteria, Actinobacteria, and Bacteroidetes accounted for more than $90 \%$ of the total community in the dry zone and the effluent water. These phyla also accounted for more than $68 \%$ of the total community in the root and mineralized zones. The genera Massilia, Mucilaginibacter, Mizugakiibacter, and Rhodoluna were most dominant in the dry, root, and mineralized zones and in the effluent water, respectively. The number of shared operational taxonomic units (OTUs) for the three zones was 241, representing $7.15 \%$ of the total observed OTUs. The number of unique OTUs in samples from dry zone, root zone, mineralized zone, and effluent water was $485,638,445$, and 383 , respectively. The samples from the root zone harbored more diverse communities than either the dry or mineralized zones. This study is the first to report on the bacterial community within the zones of a flood-and-drain media bed. Thus, this information will potentially accelerate studies on other microbial communities involved in the bioconversion of nitrogen compounds and mineralization within these types of aquaponic systems.
\end{abstract}

\section{Introduction}

Aquaponics is an integrated farming concept that combines the production of fish and hydroponic plants in systems that rely on microbial activity to improve water quality and provide nutrients to plants, in either single process loop (coupled) or two-loop systems (decoupled) [1,2]. The accumulation of uneaten food, fish feces, and organic and inorganic nitrogenous compounds in the system provides an ecosystem for microbial activity and development resulting in their conversion to plant nutrients [3]. During nitrification, ammonia, the main form of inorganic nitrogen excreted by fish, is oxidized either directly to nitrate [4] or via nitrite to nitrate, the latter being less toxic to fish, while plants can utilize it for growth $[5,6]$. An important feature of aquaponics is the reliance on microbial activity. Both autotrophic and heterotrophic bacteria occur in aquaponic systems $[6,7]$. They play a role in rhizosphere remediation, the control of abiotic stressors, and the protection of plants from pathogens [8].

Media-based growth systems are frequently used because of their simplicity and reliability [3, 9]. Media beds are designed to flood and drain or to operate as constant-flow systems [10]. Flood-and-drain cycles enable the hydroponic media bed to acquire atmospheric air which can lead to aerobic conditions in parts of the media bed [10]. Consequently, there are distinct vertically differentiated zones in media bed of flood-and-drain systems [3]. The media bed provides stability for root growth, and plants with extensive root systems typically adapt well to this environment [11]. 
Flood-and-drain aquaponic systems also provide a high surface area habitat for beneficial bacteria, as well as being a filter system for particulate suspended matter.

An international survey showed that $86 \%$ of aquaponic farmers used media-based systems, while 35\% of respondents used a combination of media bed and a raft growing technique [12]. Mchunu et al. [13] reported that $96 \%$ of survey respondents adopted media-based aquaponics in South Africa with the flood-and-drain media bed culture being the most frequently used design. There is a paucity of research on microbial diversity in aquaponic systems, particularly on the interactions between microbiota across vertical zones of the media bed that can function as microecosystems [3]. As the media bed provides a niche for diverse populations of micro- and macro-organisms, knowledge of bacterial diversity and spatial distribution of microbes in a flood-and-drain media bed will contribute to our understanding of microbial community dynamics. This fundamental knowledge should have benefits for applied research that focusses on enhancing water quality and the growth and health of fish and plants.

Metabarcoding using the 16S rRNA marker has been frequently used when studying microbial communities $[14,15]$. Next-generation sequencing (NGS) metabarcoding has been effectively used in the evaluation of microbial communities of many environmental samples and for the analysis of communities of microbes that cannot be easily cultured on selected media $[6,14,15]$. This technique has been applied to investigate the microbial diversity in different compartments and substrates of aquaponic systems such as plant roots, the system's sump, or the biological filter $[7,16,17]$, but not when comparing microbial community diversity in vertically arranged zones of the media bed.

For practical reasons, such as the demand on time and computational and monetary constraints, environmental microbiologists have reported findings related to microbial diversity using limited numbers of experimental units $[18,19]$. To contribute to the database that has been generated in studies, in which data from one point in time and from one aquaponic system were generated [7, 17], the aim of this study was to describe the diversity of bacterial communities in a flood-and-drain media bed system and to suggest biological processes that may occur in the vertical zones of this environment.

\section{Materials and Methods}

2.1. Ethics Statement. The study was conducted in accordance with the ethical guidelines for the use of animals in research and was approved by the Animal Research Ethics Committee (AREC) of the Rhodes University, South Africa (RU-AREC references: 29102018 and 2019-1145-2120).

2.2. Description of the Media Bed System. The samples analyzed in this study were collected from a mature aquaponic system (Practical Aquaponics Farm in Salem, South Africa). The system consisted of fish tanks stocked with Mozambique tilapia, Oreochromis mossambicus, two sumps, and gravel

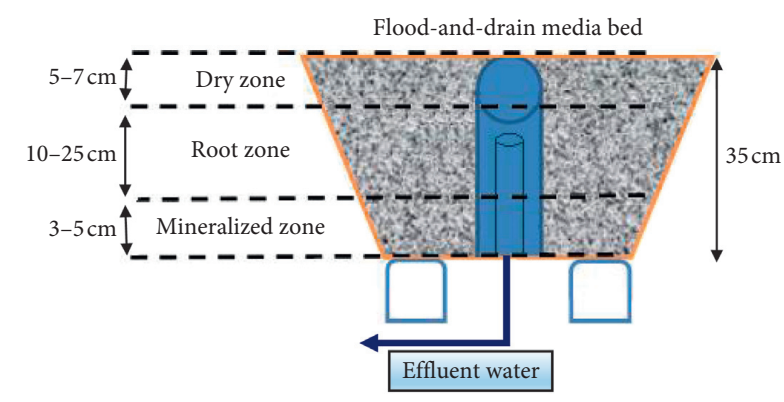

Figure 1: A schematic indicating the three zones of flood-anddrain media bed. The different zones of the flood-and-drain media bed indicated in the layout is described according to Somerville et al. [3].

beds connected to deep water culture units. Water from the fish tank continuously flowed to the sump. The water, containing organic waste solids and ammonia, was then fed to the gravel flood-and-drain media beds. Water from the media beds drained to floating raft beds. Both the gravel and floating raft beds served as mechanical and biological filters. The water was then returned to the fish tank from where the cycle was repeated. Media beds were made from food-grade plastic materials. The depth and width of the media bed were $35 \mathrm{~cm}$ and $120 \mathrm{~cm}$, respectively. Each of the media bed carried approximately $0.5 \mathrm{~m}^{3}$ of wet gravel or $24 \mathrm{~m}^{2}$ of the biological surface area. Gravel stones measuring approximately $19 \mathrm{~mm}$ were used as media within the grow bed. The number of flood cycles was maintained at four cycles per hour and during the time of sampling, the average $\mathrm{pH}$ of the effluent water was 6.8 .

2.3. Sediment and Water Sampling. Gravel stone samples were collected using a sterilized stainless-steel shovel. Triplicate samples (200 g each) from the top dry zone (5-7 cm depth), root zone (10-25 cm depth), and the bottom mineralized zone $(3-5 \mathrm{~cm}$ depth) were collected from a flood-and-drain media bed (Figure 1). In addition, $2 \mathrm{~L}$ of water was collected in sterile Pyrex bottles from the grow bed through the outlet pipe. The triplicate samples were taken to reflect a representation of the microbial population present in each zone. The samples were transferred to sterile plastic bags, and excess water was removed. All samples were transported on ice to the laboratory within $2 \mathrm{~h}$, kept at $2^{\circ} \mathrm{C}$, and prepared for analyses the following day.

2.4. DNA Extraction. In order to ensure the harvest of a maximum quantity of bacteria, pooled gravel samples for each zone were transferred to a $250 \mathrm{~mL}$ sterile beaker containing $150 \mathrm{~mL}$ of sterilized water. After vigorous stirring for $10 \mathrm{~min}, 100 \mathrm{~mL}$ of water from each beaker was filtered through $0.2 \mu \mathrm{m}$ filters (Supor ${ }^{\circledR}$ Membrane disc filters, PALL Life Sciences, USA) with a vacuum pump (Rocker Model 801 , vacuum pump 167801-22, Taiwan). This procedure was repeated three times for each sample. Water samples were also filtered through $0.2 \mu \mathrm{m}$ filters with the vacuum pump. All filters corresponding to different samples were 


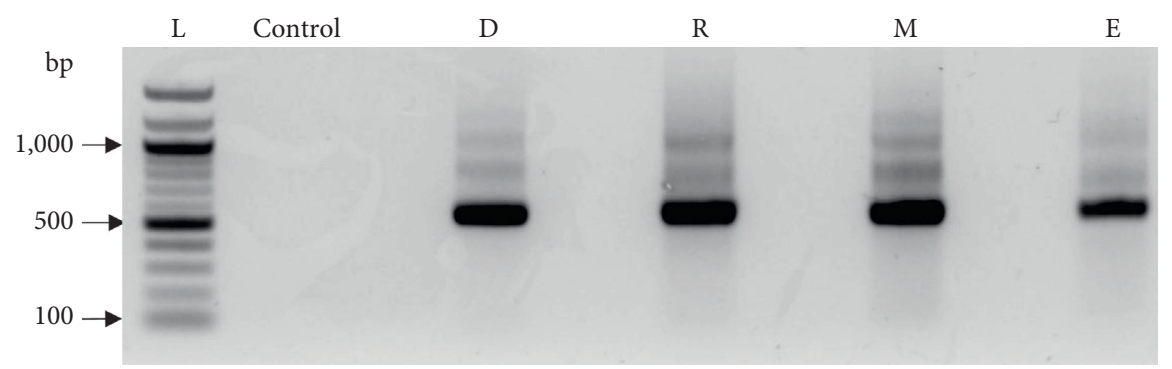

Figure 2: Agarose gel electrophoresis of the PCR products amplified from the samples collected from different zones of flood-and-drain media bed. Lane $\mathrm{L}$ shows the 1,000 bp ladder, followed by a negative control. Lanes $\mathrm{D}, \mathrm{R}, \mathrm{M}$, and $\mathrm{E}$ are the amplification products from dry zone, root zone, mineralized zone, and effluent water, respectively.

transferred to ZR Bashing Bead ${ }^{\mathrm{TM}}$ lysis tubes comprising $0.5 \mathrm{~mm}$ beads. DNA was extracted from microbial cells associated with filter materials using a ZymoBIOMICS ${ }^{\mathrm{TM}}$ DNA Miniprep Kit (USA) according to the manufacturer's instructions. The extracted DNA concentration was measured using a NanoDrop ${ }^{\mathrm{TM}} 2000$ (Thermo Fisher Scientific, USA), run on $1 \%$ agarose gel electrophoresis, and then visualized using a ChemiDoc ${ }^{\mathrm{TM}} \mathrm{XRS}+($ Bio-Rad, Hercules, CA, USA).

2.5. PCR Amplification and Purification. Amplification of the variable region $\mathrm{V} 3-\mathrm{V} 4$ of the $16 \mathrm{~S}$ rRNA was performed using a universal primer set $16 \mathrm{Sa}-\mathrm{F}$ ( $5^{\prime}$-TCG TCG GCA GCG TCA GAT GTG TAT AAG AGA CAG CAG CAG CCG CGG TAA- $3^{\prime}$ ) and 16Sa-R (5'-GTC TCG TGG GCT CGG AGA TGT GTA TAA GAG ACA GGT AAG GTT CYT CGC GT - $3^{\prime}$ ). Each reaction mixture contained $50 \mathrm{ng}$ of template DNA, $0.3 \mu \mathrm{M}$ of each oligonucleotide primer, $0.3 \mathrm{mM}$ of dNTP mix, $1 \times$ reaction buffer, $2.5 \mathrm{mM}$ of $\mathrm{MgCl}_{2}$, and 1 unit of Accupol ${ }^{\mathrm{TM}}$ DNA polymerase, and PCR-grade water was added to a total of $25 \mu \mathrm{L}$. A control, in which nuclease-free water was added instead of DNA, was included in the samples used for PCR. The samples were amplified using a $\mathrm{T} 100^{\mathrm{TM}}$ Thermal Cycler (Bio-Rad Laboratories, Hercules, CA, USA) with the following conditions: initial denaturation at $98^{\circ} \mathrm{C}$ for $5 \mathrm{~min} ; 7$ cycles of $98^{\circ} \mathrm{C}$ for $45 \mathrm{~s}, 45^{\circ} \mathrm{C}$ for $30 \mathrm{~s}$, and $72^{\circ} \mathrm{C}$ for $1 \mathrm{~min}$ followed by 18 cycles at $98^{\circ} \mathrm{C}$ for $30 \mathrm{~s}, 50^{\circ} \mathrm{C}$ for $30 \mathrm{~s}$, and $72^{\circ} \mathrm{C}$ for $1 \mathrm{~min}$. A final extension was done at $72^{\circ} \mathrm{C}$ for $5 \mathrm{~min}$. Electrophoresis was performed for $45 \mathrm{~min}$ at $100 \mathrm{~V}$. PCR products were visualized on a $1 \%$ agarose gel under a ChemiDoc ${ }^{\mathrm{TM}} \mathrm{XRS}+$ (Bio-Rad, Hercules, CA, USA) (Figure 2). The expected size of amplicons was approximately $550 \mathrm{bp}$, which were excised from the gel and purified using the Zymoclean ${ }^{\mathrm{TM}}$ Gel DNA recovery Kit (Zymo Research) according to kit instructions. The gel purification was confirmed by electrophoresis on a $1 \%$ agarose gel under a ChemiDoc ${ }^{\mathrm{TM}} \mathrm{XRS}+$ system (Bio-Rad, Hercules, CA, USA). A final volume of $15 \mu \mathrm{L}$ of purified amplicon products was obtained. After purification, DNA was quantified using the PicoGreen assay (Invitrogen) and the quality was checked using a bioanalyzer (Agilent). The Illumina MiSeq integrated next-generation sequencer (Illumina ${ }^{\circledR}$ Inc., USA) and a MiSeq Reagent Kit v3 (600 cycles) (Illumina ${ }^{\circledR}$ Inc. USA) were used to sequence the prepared amplicon libraries. The Nextera XT adaptors were used to multiplex the amplicon libraries before loading onto the MiSeq and sequencing.

2.6. Data Curation and Analyses. The sequence FASTQ files from the Illumina MiSeq were analyzed using Mothur platform version 1.41.3 release [20]. Dataset curation included removal of reads shorter than 100 bases, reads longer than 500 bases, and those with ambiguous nucleotides. Chimeric sequences were removed using the VSEARCH [21] command within Mothur. Subsequently, unique reads were checked for chimeric sequences followed by their removal from the datasets. Classification of the sequence reads was done using Naïve Bayesian classifier against the Silva bacterial database (release version 132) and plotted as a percentage of total reads per sample. Nonbacterial, chloroplast, and mitochondrial operational taxonomic units (OTUs) were considered as contaminating sequences and removed prior to downstream analysis. All OTUs were clustered at a cutoff of 0.03 . The taxonomical classification was performed to genus level (Supplementary Table S1). Alpha diversity metrics (InvSimpson, Chao1, Shannon, and Good's coverage index) were calculated using the Mothur platform. The analysis of the common and unique OTUs was conducted to investigate the media bed bacterial communities through a Venn diagram. Chaol was used to estimate species richness, and Shannon's index was used to indicate species diversity. Sequences of 50 dominant bacterial OTUs were further compared to the nucleotide database using NCBI-BLAST tool, and the results are provided in Supplementary Table S2.

\section{Results}

3.1. Taxonomic Assignment of Reads. Metabarcoding analysis of $16 \mathrm{~S}$ rRNA V3-V4 regions revealed a total of 156,865 raw sequences from four samples with the number of sequences ranging from 26,646 to 63,416 per individual sample (Table 1). After removing poor-quality reads, a total of 125,521 sequences were obtained. On removal of chimeras, 42,251, 25,893, 18,358, and 20,664 sequences were collected from dry zone, root zone, mineralized zone, and effluent water, respectively, resulting in 107,166 sequences from all samples. The total percentage of sequences flagged as chimeric was $14.6 \%$. 
TABLE 1: Summary of metagenomic data for the vertical zones and samples from the effluent water.

\begin{tabular}{|c|c|c|c|c|c|}
\hline Zone/source & $\begin{array}{c}\text { Number of raw } \\
\text { sequences }\end{array}$ & $\begin{array}{c}\text { Number of } \\
\text { sequences before } \\
\text { chimeric }\end{array}$ & $\begin{array}{c}\text { Number of } \\
\text { sequences after } \\
\text { chimeric }\end{array}$ & $\begin{array}{l}\text { Chloroplast and } \\
\text { mitochondria sequences }\end{array}$ & $\begin{array}{l}\text { Number of reads after } \\
\text { screening and filtering }\end{array}$ \\
\hline Dry zone & 63,416 & 49,368 & 42,251 & 111 & 41,886 \\
\hline Root zone & 37,446 & 30,263 & 25,893 & 171 & 23,794 \\
\hline $\begin{array}{l}\text { Mineralized } \\
\text { zone }\end{array}$ & 29,357 & 23,797 & 18,358 & 125 & 16,761 \\
\hline Effluent water & 26,646 & 22,093 & 20,664 & 2 & 20,242 \\
\hline
\end{tabular}

Total raw sequences: 156,865; total number of sequences before chimeras: 125,521 ; total number of sequences after removal of chimeras: $107,166$.

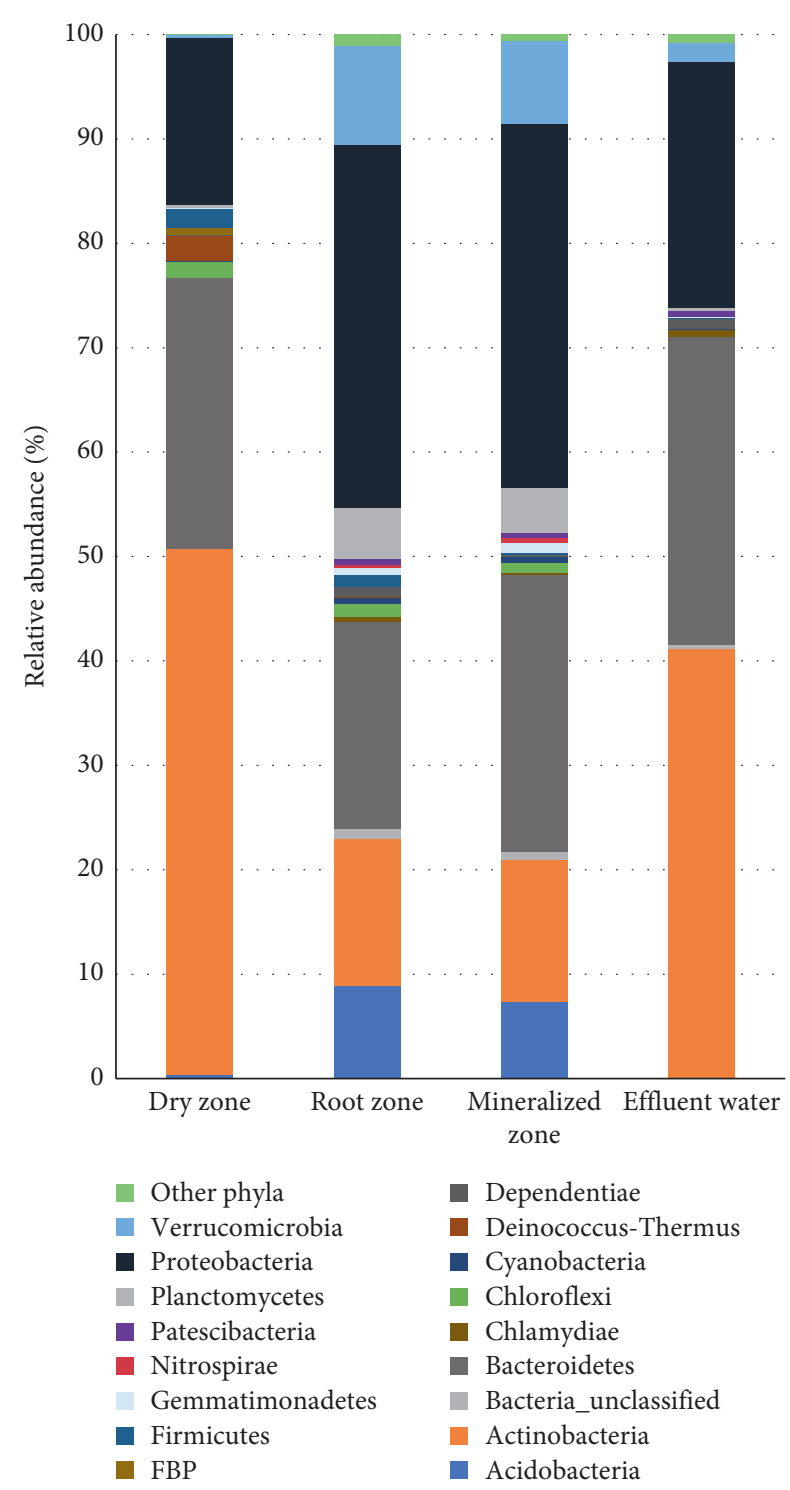

Figure 3: Classification of reads from dry zone, root zone, mineralized zone, and effluent water from the media grow bed at phylum level indicated as percentage of the population. Phyla that were represented in all zones below $0.5 \%$ of total community are displayed under "other phyla," which contained the phyla Armatimonadetes, Cloacimonetes, Epsilonbacteraeota, Elusimicrobia, Fibrobacteres, Fusobacteria, Hydrogenedentes, Kiritimatiellaeota, Lentisphaerae, Omnitrophicaeota, Spirochaetes, Tenericutes, candidate division BRC1, WPS-2, and FCPU426.
3.2. Predominant Phyla and Genera. Although the taxonomic composition of the bacterial community was similar between zones and effluent water, the frequency distribution of bacterial phyla differed between the three zones. All sequences were identified into 32 phyla, but only 17 had a relative abundance of more than $0.5 \%$ (Figure 3 ). The major phylum groups were Proteobacteria, Actinobacteria, and Bacteroidetes, accounting for more than $90 \%$ of the total community in the dry zone and effluent water. These phyla also accounted for more than $68 \%$ in the root and mineralized zones. Only a small fraction $(0.02 \%-1.01 \%)$ of the total sequences for the samples could not be classified into any known phyla and were therefore labelled as unclassified sequence (Figure 3). The dry zone samples were mainly composed of Actinobacteria (50.28\%), Bacteroidetes (26.04\%), and Proteobacteria (16.09\%). The root zone was mostly comprised of Proteobacteria (34.86\%), Bacteroidetes (19.76\%), and Actinobacteria (14.04\%) while the mineralized zone was mostly comprised of Proteobacteria (34.82\%), Bacteroidetes (26.49\%), and Actinobacteria (13.60\%). Effluent water was mainly characterized by Actinobacteria (41.10\%), Bacteroidetes (29.50\%), and Proteobacteria (23.54\%).

Only 25 genera were dominant with a relative abundance of more than $1 \%$ of total bacteria reads (Table 2 ). The three media bed zones were dominated by different genera that included Hymenobacter (12.27\%), Massilia (8.35\%), Pontibacter $(6.72 \%)$, and Nocardioides (6.66\%) for the dry zone; Mucilaginibacter (3.17\%) and Rhodanobacter (2.21\%) for the root zone; and Mizugakiibacter (2.36\%), Heliimonas (1.70\%), and Flavobacterium (1.11\%) for the mineralized zone (Table 2$)$. The effluent water samples contained large numbers of Rhodoluna (26.64\%), Flavobacterium (23.10\%), and Polynucleobacter (10.47\%).

3.3. Unique Bacterial Genera. Among the bacteria with an overall abundance of more than $1 \%$ of the total community, some unique genera were found in samples from media bed zones and effluent water (Table 3). Among them, 16 special genera were obtained in both the root zone and the mineralized zone, while ten unique genera were detected in the dry zone. Additionally, five unique genera were found in the effluent water. In the three zones, the main functions of the unique genera were divided into activities such as phosphorus solubilizing, production of antimicrobial substances, decomposition of organic matter, iron cycling, denitrification, nitrogen fixation, bioremediation, and production of secondary metabolites. 
TABLE 2: Distribution of different genera in the three media bed zones and effluent water.

\begin{tabular}{|c|c|c|c|c|}
\hline \multirow{2}{*}{ Genera } & \multicolumn{3}{|c|}{ Relative abundance (\%) } & \multirow[b]{2}{*}{ Effluent wate } \\
\hline & Dry zone & Root zone & Mineralized zone & \\
\hline Acidibacter & 0.00 & 2.04 & 0.71 & 0.00 \\
\hline Actinomycetospora & 1.57 & 0.01 & 0.01 & 0.00 \\
\hline Aeromicrobium & 2.31 & 0.03 & 0.05 & 0.00 \\
\hline Blastococcus & 1.00 & 0.01 & 0.02 & 0.00 \\
\hline Chujaibacter & 0.11 & 2.14 & 0.55 & 0.00 \\
\hline Dokdonella & 0.00 & 0.67 & 1.34 & 0.02 \\
\hline Flavobacterium & 0.21 & 0.89 & 1.11 & 23.10 \\
\hline Flexivirga & 3.13 & 0.27 & 0.42 & 0.00 \\
\hline Friedmanniella & 1.42 & 0.01 & 0.04 & 0.00 \\
\hline Hymenobacter & 12.27 & 0.04 & 0.08 & 0.00 \\
\hline Jatrophihabitans & 1.23 & 0.56 & 0.70 & 0.00 \\
\hline Marmoricola & 3.14 & 0.17 & 0.35 & 0.00 \\
\hline Massilia & 8.35 & 0.03 & 0.05 & 0.77 \\
\hline Microbacterium & 2.14 & 0.70 & 0.85 & 0.01 \\
\hline Mizugakiibacter & 0.01 & 1.26 & 2.36 & 0.03 \\
\hline Modestobacter & 2.21 & 0.02 & 0.05 & 0.00 \\
\hline Mucilaginibacter & 0.27 & 3.17 & 1.70 & 0.03 \\
\hline Mycobacterium & 0.61 & 2.07 & 0.81 & 0.88 \\
\hline Nocardioides & 6.66 & 0.36 & 0.98 & 0.00 \\
\hline Opitutus & 0.00 & 0.41 & 1.14 & 0.14 \\
\hline Pontibacter & 6.72 & 0.05 & 0.10 & 0.00 \\
\hline Pseudonocardia & 1.71 & 0.04 & 0.13 & 0.00 \\
\hline Rhodanobacter & 0.25 & 2.21 & 0.40 & 0.01 \\
\hline Rhodoluna & 0.00 & 0.02 & 0.27 & 26.64 \\
\hline Rudaea & 0.00 & 0.47 & 1.34 & 0.04 \\
\hline
\end{tabular}

Only genera with relative abundance of $\geq 1 \%$ of the total community in at least one of the investigated samples are reported.

TABLE 3: Comparison of microbial genera among media bed zones and effluent water.

\begin{tabular}{|c|c|c|c|c|c|}
\hline Genus & Function* & Dry zone & Root zone & Mineralized zone & Effluent water \\
\hline Acidibacter & Iron cycling & - & + & + & - \\
\hline Actinomycetospora & Associative nitrogen fixation & + & + & + & - \\
\hline Aeromicrobium & Nitrogen fixation & + & + & + & - \\
\hline Blastococcus & Decomposition of organic matter & + & + & + & - \\
\hline Dokdonella & Denitrification & - & + & + & + \\
\hline Flexivirga & Degradation of organic matter & + & + & + & - \\
\hline Friedmanniella & Production of antimicrobial substances & + & + & + & - \\
\hline Heliimonas & Breakdown of complex organic compounds & - & + & + & + \\
\hline Jatrophihabitans & Production of secondary metabolites & + & + & + & - \\
\hline Marmoricola & Denitrification & + & + & + & - \\
\hline Modestobacter & Phosphate solubilization & + & + & + & - \\
\hline Nocardioides & Production of antibiotics, lignocellulose decomposition & + & + & + & - \\
\hline Opitutus & Denitrification, polysaccharide degradation & - & + & + & + \\
\hline Pseudonocardia & Nitrogen fixation & + & + & + & - \\
\hline Rhodoluna & $\begin{array}{c}\text { Ability to produce secondary metabolites that have antibiotic } \\
\text { properties }\end{array}$ & - & + & + & + \\
\hline Rudaea & Decomposition of plant residues & - & + & + & + \\
\hline Hymenobacter & Decomposition of plant residues & + & + & + & - \\
\hline Pontibacter & Nitrogen fixation & + & + & + & - \\
\hline
\end{tabular}

$+:$ presence of the genus in the environment; -: absence of the genus in the environment. ${ }^{*}$ The function description of each genus is based on Taxonomic Outline of the Prokaryotes, Bergey's Manual of Systematic Bacteriology by Holt et al. [22], and the Prokaryotes by Dworkin et al. [23].

3.4. Bacterial Community Composition and Similarity Analysis. The number of shared OTUs for the three zones was 241 representing $7.15 \%$ of the total observed OTUs (3371) (Venn diagram, Figure 4). In addition, the unique OTU numbers in the grow bed samples from the dry zone, the root zone, the mineralized zone, and the effluent water were 485 , 638,445 , and 383 , respectively. The number of OTUs in the groups of the dry zone, root zone, mineralized zone, and effluent water was 933, 1,830, 1,715, and 857, respectively.

3.5. Diversity Analysis for Bacterial Communities. Each sample had coverage greater than $96 \%$ of Good's coverage, indicating that the sequencing depth was sufficient (Table 4). 
TABLE 4: Richness and diversity indices of bacterial communities for aquaponic samples collected from three media bed zones and effluent water.

\begin{tabular}{lccccc}
\hline Zone & Chao1 & InvSimpson & Shannon & Good's coverage (\%) & Observed richness \\
\hline Dry zone & $1,489.80$ & 80.69 & 5.24 & 98 & 933 \\
Root zone & $2,691.12$ & 218.89 & 6.26 & 96 & 1,830 \\
Mineralized zone & $2,610.18$ & 93.21 & 5.89 & 96 & 1,715 \\
Effluent water & $1,421.97$ & 7.33 & 3.21 & 98 & 857 \\
\hline
\end{tabular}

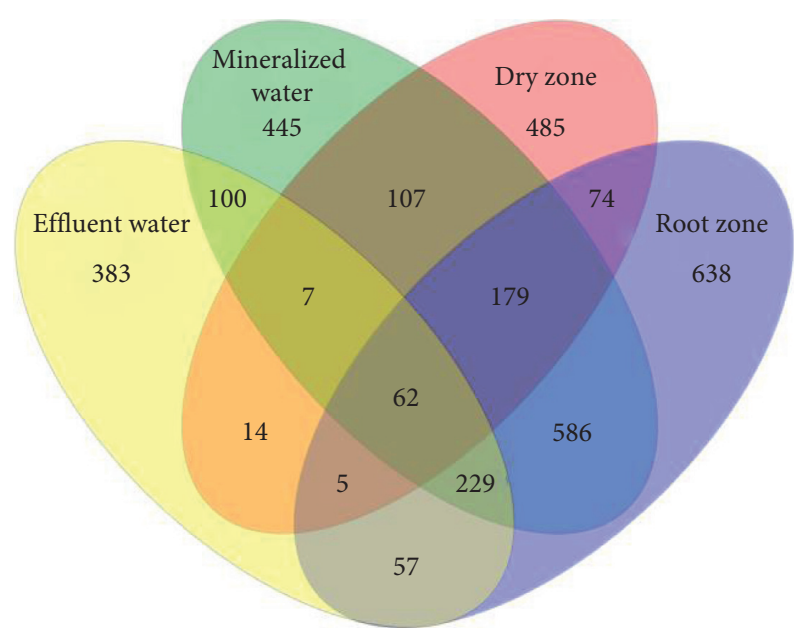

FIGURE 4: Venn diagram showing the unique and shared OTUs in samples from three media bed zones and the effluent water in an aquaponic system.

The Shannon index for the root zone was 6.26 suggesting a relatively higher diversity of bacterial sequences in this zone than in either the dry zone or mineralized zone. The community richness (total number of observed OTUs) and InvSimpson were highest in the root zone. Chaol analysis conducted for estimating bacterial community richness indicated 1,489.80 phylotypes in the dry zone; 2,691.12 phylotypes in the root zone; 2,610.18 phylotypes in the mineralized zone; and 1,421.97 phylotypes in effluent water. Compared with the dry and the mineralized zones, the root zone had the highest OTU richness and bacterial community diversity.

Rarefaction curves were used to compare species richness in the three zones and effluent water (Supplementary Figure S1). The curves did not approach the asymptote, which indicated that each zone showed highest completeness of species. The curves indicated that OTUs were higher in samples from the root zone than the mineralized and dry zones (Supplementary Figure S1).

As shown in Figure 5(a), the abundances are exhibited in a heat map for the most abundant 50 OTUs. The pale light blue color illustrated highest abundance, and the black color expressed lowest abundance of species. The heat map indicates that most species in the root and mineralized zones had a higher relative abundance than the samples from the dry zone and effluent water. The dendrogram indicates that samples from root and mineralized zones had high similarity, while the dry zone was the most distantly related from all other zones including the effluent water (Figure 5(b)).

\section{Discussion}

\subsection{The Bacterial Communities in the Vertical Zones and Effluent Water of a Flood-and-Drain Media Bed}

4.1.1. Dry Zone. The top $5-7 \mathrm{~cm}$ of the media grow bed was defined as the dry zone. This zone functions as a light barrier by preventing light from reaching the nutrient-rich water in the root zone. This zone protects light-sensitive beneficial bacteria and prevents algal growth [3]. The low moisture content in this zone reduces the growth of fungi and harmful bacteria. At the genus level, the genera Pontibacter, Massilia, Modestobacter, and Hymenobacter were the most dominant in the dry zone. Members of the genus Massilia have been reported in diverse environments [24]. This genus has been isolated from the rhizosphere and roots of plant species and appears to tolerate adverse environmental conditions [24]. Massilia utilizes root metabolites, degrades aromatic compounds, and produces antimicrobial substances $[25,26]$. The reduced abundance of Massilia in other zones may be related to interspecies competition for resources, although this hypothesis needs to be tested in future studies. In addition, members of the genera Pontibacter, Modestobacter, and Hymenobacter are associated with harsh environmental conditions, including desert soils and surfaces of rocks $[27,28]$. Thus, abundance of these genera in the dry zone may be related to the low water content and nutrient availability and high solar radiation.

4.1.2. Root Zone. The root zone has a high moisture content. The depth for the root zone ranges from 10 to $25 \mathrm{~cm} \mathrm{[3].}$ Most of the biological activities occur in the root zone. The samples from the root zone contained high abundance of Mucilaginibacter and Chujaibacter. The genus Mucilaginibacter degrades polysaccharides using carbohydrate-active enzymes (CAZymes) [29]. They are regarded as cellulolytic bacteria that have an active role in plant biomass decomposition [30]. Thus, the dominance of Mucilaginibacter in this zone may be significant in the digestion and breakdown of organic matter and the mineralization process. The root zone also had a relatively high abundance of the putative denitrifiers Rhodanobacter and Dokdonella. This may be related to the setup of the flood-and-drain media growing technique. Media-based aquaponic systems may have pockets of anoxic zones that may provide favorable conditions for denitrification $[31,32]$. The samples from the root zone had a relatively high abundance of Acidibacter, a ferric iron reducer [33]. Iron is an essential micronutrient for plant and fish growth in aquaponics [34]. It is typically available as 


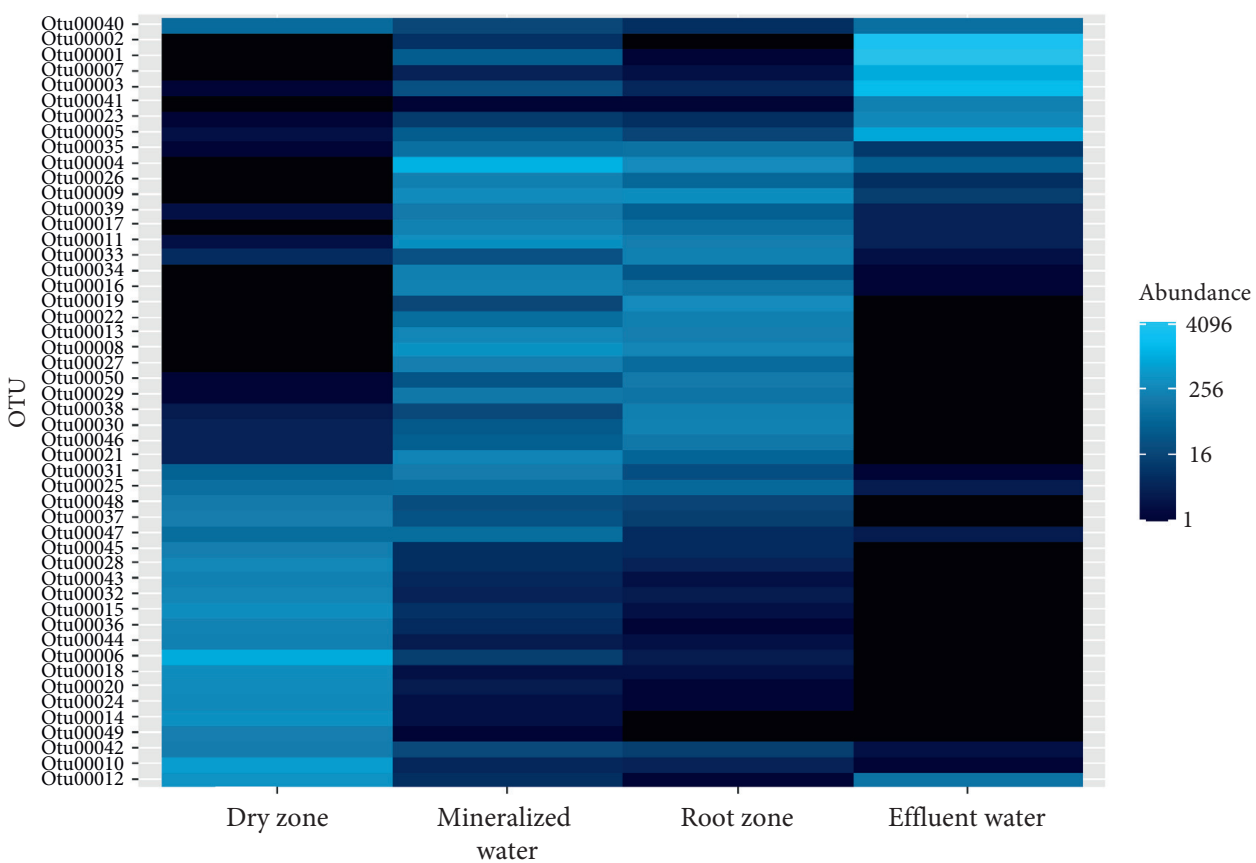

(a)

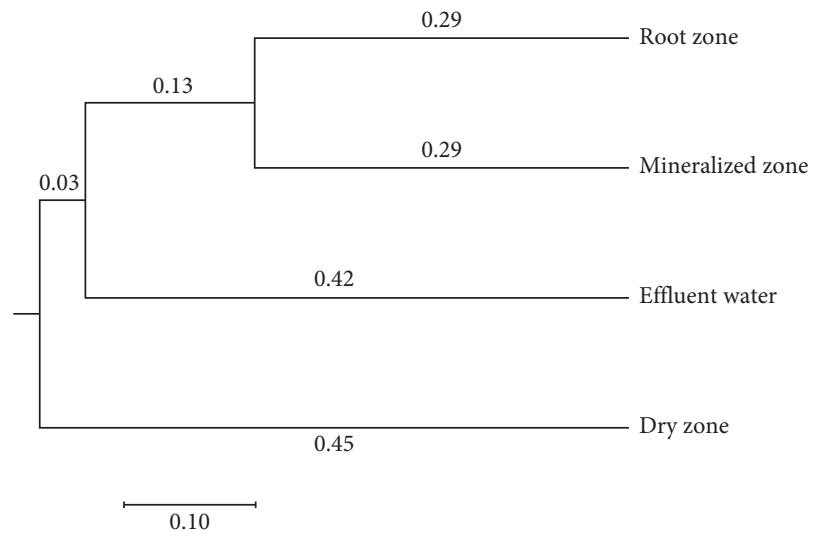

(b)

FIgURE 5: (a) A heat map showing the dominant OTUs and their relative abundance in the grow bed and effluent samples. (b) A dendrogram showing similarity of the aquaponic samples from three media bed zones and effluent water based on Jclass and Thetayc calculators in Mothur. Dominant bacterial OTUs are provided in Supplementary Table S1.

soluble ferrous iron $\left(\mathrm{Fe}^{2+}\right)$ and insoluble oxidized ferric iron $\left(\mathrm{Fe}^{3+}\right)$. However, $\mathrm{Fe}^{3+}$ forms insoluble oxides and hydroxides, limiting its bioavailability [34]. Thus, the presence of Acidibacter may indicate Fe cycling in an aquaponic system. The aquaponic system in this study received Fe-EDDHA of $2 \mathrm{mg} / \mathrm{L}$ approximately every third week.

4.1.3. Mineralized Zone. The bottom zone with an optimal depth range of 3 to $5 \mathrm{~cm}$ is responsible for the slow release of readily available nutrients into the system [3]. This zone includes mainly heterotrophic bacteria responsible for breaking down the waste into smaller molecules that can be absorbed by plants. The samples from the mineralized zone contained abundance of Flavobacterium, Rurimicrobium, Rudaea, Mizugakiibacter, and Heliimonas. Rurimicrobium and Heliimonas belong to Chitinophagaceae and are reported to produce antifungal metabolites [35]. Mizugakiibacter are heterotrophic bacteria typically found in the sediment of freshwater ecosystems [36]. Their high abundance in the mineralized zone might be caused by the solid wastes which tend to accumulate in this zone. Flavobacterium were more represented in samples from the mineralized zone than in the dry zone or root zone. Flavobacterium have been associated with the capacity to degrade complex organic compounds [37]. Under natural conditions, bacteria of the genus Flavobacterium mineralize organic substrates (e.g., carbohydrates, amino acids, and proteins) and degrade organic matter and some organisms (bacteria, fungi, and insects) using a variety of enzymes [37]. This genus is particularly concentrated in areas where solid waste accumulates [15]. The mineralized zone normally 
contains solid waste, and this may explain the relatively high abundance of Flavobacterium in this zone. Furthermore, the samples from the mineralized zone contained high abundance of Rudaea. The genus Rudaea belongs to the cellulolytic bacteria [38] and cellulose is mainly degraded in an aerobic environment. In soil-based studies, cellulolytic bacteria helped to regulate the carbon cycle through the decomposition of plant residues in the soil ecosystem $[38,39]$. The relatively high abundance of Rudaea in this zone may be important for degrading organic matter and conversion of solid organic waste into useable nutrients for plants.

4.1.4. Effluent Water. At genus level in the effluent water samples, Rhodoluna, Flavobacterium, Polynucleobacter, and Aurantimicrobium were dominant. These genera have been widely detected in freshwater environments [40-42]. Members of genus Polynucleobacter are capable of utilizing photo-oxidation products of humic substances, and some strains use light as an energy source [42]. Additionally, this bacterial group is considered as a good indicator for water quality through nitrogen and carbon cycling [41, 42]. Therefore, the presence of Polynucleobacter is a novel result because water quality variables are one of the main environmental considerations for optimizing aquaponic production [43]. The genera Rhodoluna and Aurantimicrobium are known as actinorhodopsin (ActR) encoding photoheterotrophic bacteria that can survive under low nutrient and energy conditions [44, 45]. ActR is a light-driven proton pump [44] and despite its presence in freshwater Actinobacteria, little is known about its ecological role including the range of wavelengths supporting the ActR proton pump activity $[42,46]$. Therefore, the high abundance of Rhodoluna in effluent water may be related to ActR genes that enable this genus to successfully compete in a wide range of freshwater environments. In addition, the high abundance of the genus Flavobacterium in effluent water signifies degradation processes of organic matter in the flood-and-drain media bed.

4.2. Potential Influence of Bacteria on Media Bed Ecological Processes. Aquaponic gravel media beds are the habitat of a complex bacterial ecosystem. These microbial communities contribute to aquaponics through nitrification, nutrient conversion, regulation of organic matter decomposition, and mineralization of nutrients [10]. Such processes are vital for the functioning and health of aquaponic ecosystems. The present study explored the bacterial community structure of three vertically arranged zones of a flood-and-drain media bed from a mature coupled aquaponic system. The Shannon indices demonstrated that the bacterial richness in floodand-drain media bed aquaponic system varies with depth. The root zone had the highest OTU richness and bacterial community diversity. The flood and drain action in the grow bed makes it highly aerobic, thereby providing a favorable environment for autotrophic and heterotrophic bacteria to form symbiotic relationships with the roots and perform critical functions of nitrification and mineralization, respectively. Additionally, root exudates released by plants might enhance microbial growth and distribution. For the mineralized zone, the design of the gravel bed in the floodand-drain media bed aquaponic system ensures that mineral-rich water is being removed and replaced with new oxygenated water in this zone, providing conditions for conversion of solid wastes into useable nutrients and mineral elements for plants. The dry zone had the lowest bacterial community diversity. Being a unique zone that covers the root and mineralized zones from direct light and evaporation, it is likely that the conditions were characterized by relatively high temperature and direct sunlight, thus affecting the bacterial compositions [3].

Proteobacteria and Bacteroidetes were abundant across the zones and in the effluent water. These phyla respond rapidly to carbon sources and are considered as $r$-strategists, as they are fast-growing bacteria $[16,47]$. The enrichment of Proteobacteria and Bacteroidetes in different units of an aquaponic system such as in the sump and biofilter was reported by Schmautz et al. [7] and Eck et al. [17], which is similar to the findings in our study. These phyla are mostly responsible for nitrogen cycling in aquaponic systems $[7,16]$. Ammonium excreted by fish or derived from organic material is oxidized to nitrite and then nitrate by ammoniaoxidizing and nitrite-oxidizing bacteria belonging to the phylum Proteobacteria [3]. Under anoxic conditions, denitrifiers belonging to the phylum Bacteroidetes transform nitrate to nitrite, nitric oxide, nitrous oxide, and nitrogen gas [16].

A high proportion of reads from the dry zone was assigned to the phylum Actinobacteria. Actinobacteria is one of the largest phyla with members from a wide range of environmental sources, including soil surface [48]. They have been reported to be capable of producing a wide range of secondary metabolites $[48,49]$. Actinobacteria produce extracellular hydrolytic enzymes, which degrade animal and plant residues and other organic compounds, allowing them to survive in environments with low nutrient levels $[50,51]$. The presence of plant residues and probably the low nutrient levels in the dry zone might influence Actinobacteria to thrive in this type of environment. The relative abundance of Nitrospirae was relatively low, but samples from mineralized zones contained a higher percentage $(0.5 \%$ of the total community) than the other zones.

\section{Conclusions and Future Perspectives}

The metabarcoding analysis presented here provides the first insight into the bacterial community of different zones of a flood-and-drain media bed system. The grow bed zones influenced the bacterial community structure. Specifically, the samples from the root zone harbored more diverse bacterial communities than the dry and mineralized zones. This could be due to similar conditions of nutrient-rich water that may increase niche overlap for more complex interactions between species. The findings were from samples collected from a single system at a single point in time; therefore, further research involving a more comprehensive sampling of a single system over time would be required to 
study the influence of sampling time on microbial diversity. A comparison between different media (e.g., pumice stones and expanded clay pebbles) and bacterial communities may yield insights into the effects of media on the bacterial ecology within this unique environment. Further studies to assess the relationship between different metabolites produced in different zones and bacterial community compositions are recommended.

\section{Data Availability}

The sequence datasets generated in this study have been deposited in the sequence reads archive (SRA) database of the National Center of Biotechnology Information (SRA accession: SRR11855284).

\section{Conflicts of Interest}

The authors declare that they have no conflicts of interest regarding the publication of this article.

\section{Acknowledgments}

The authors acknowledge the Aquatic Genomics Research Platform at the South African Institute of Aquatic Biodiversity (SAIAB) and Dr Gwynneth F. Matcher for his assistance in the high-throughput sequencing application. The authors also acknowledge Mr Martin Fick of Practical Aquaponics and thank him for access to aquaponic gravel and water samples. This study was carried out with financial support from Rhodes University and the DAAD Scholarship Programme for In-Region Rhodes University of South Africa, 2018.

\section{Supplementary Materials}

Table S1: taxonomic classification of the 50 most abundant OTUs. The taxonomical classification was performed to genus level. The dominant bacterial OTUs are provided in the table. Table S2: bacterial OTUs and their most related species. Sequences of 50 dominant bacterial OTUs were further compared to the nucleotide database using NCBIBLAST tool, and the results are provided in the table. Figure S1: rarefaction analysis of samples from three grow bed zones and the effluent water in an aquaponic system. Rarefaction curves were used to compare species richness in the three zones and effluent water. (Supplementary Materials)

\section{References}

[1] J. E. Rakocy, M. P. Masser, and T. M. Losordo, Recirculating Aquaculture Tank Production Systems: Aquaponics-Integrating Fish and Plant Culture, SRAC Publication No. 454, Southern Regional Aquaculture Center, Stoneville, MS, USA, 2006.

[2] S. Goddek, A. Joyce, S. Wuertz et al., "Decoupled aquaponics systems," in Aquaponics Food Production Systems, S. Goddek, A. Joyce, B. Kotzen, and G. Burnell, Eds., pp. 202-204, Springer, Cham, Switzerland, 2019.

[3] C. Somerville, M. Cohen, E. Pantanella, A. Stankus, and A. Lovatelli, "Small-scale aquaponic food production: integrated fish and plant farming," in FAO Fisheries and Aquaculture Technical Paper 589, pp. 35-61, Food and Agriculture Organization of the United Nations, New York, NY, USA, 2014.

[4] H. Daims, E. V. Lebedeva, P. Pjevac et al., "Complete nitrification by Nitrospira bacteria," Nature, vol. 528, pp. 555-559, 2015.

[5] R. V. Tyson, D. D. Treadwell, and E. H. Simonne, "Opportunities and challenges to sustainability in aquaponic systems," HortTechnology, vol. 21, no. 1, pp. 6-13, 2011.

[6] P. Munguia-Fragozo, O. Alatorre-Jacome, E. Rico-Garcia et al., "Perspective for aquaponic systems: "Omic" technologies for microbial community analysis," BioMed Research International, vol. 2015, Article ID 480386, 10 pages, 2015.

[7] Z. Schmautz, A. Graber, S. Jaenicke, A. Goesmann, R. Junge, and T. H. M. Smits, "Microbial diversity in different compartments of an aquaponics system," Archives of Microbiology, vol. 199, no. 4, pp. 613-620, 2017.

[8] R. Mendes, P. Garbeva, and J. M. Raaijmakers, "The rhizosphere microbiome: significance of plant beneficial, plant pathogenic, and human pathogenic microorganisms," FEMS Microbiology Reviews, vol. 37, no. 5, pp. 634-663, 2013.

[9] C. R. Engle, Economics of Aquaponics, Southern Regional Aquaculture Center, Stoneville, MS, USA, 2015.

[10] W. A. Lennard and B. V. Leonard, "A comparison of reciprocating flow versus constant flow in an integrated, gravel bed, aquaponic test system," Aquaculture International, vol. 12, no. 6, pp. 539-553, 2005.

[11] C. Maucieri, C. Nicoletto, R. Junge, Z. Schmautz, P. Sambo, and M. Borin, "Hydroponic systems and water management in aquaponics: a review," Italian Journal of Agronomy, vol. 13, no. 1, pp. 1-11, 2018.

[12] D. C. Love, J. P. Fry, L. Genello et al., "An international survey of aquaponics practitioners," PLoS One, vol. 9, no. 7, Article ID e102662, 2014.

[13] N. Mchunu, G. Lagerwall, and A. Senzanje, "Aquaponics in South Africa: results of a national survey," Aquaculture Reports, vol. 12, pp. 12-19, 2018.

[14] Y. S. Bukin, Y. P. Galachyants, I. V. Morozov, S. V. Bukin, A. S. Zakharenko, and T. I. Zemskaya, "The effect of 16s rRNA region choice on bacterial community metabarcoding results," Scientific Data, vol. 6, no. 190007, pp. 1-14, 2019.

[15] A. Joyce, M. Timmons, S. Goddek, and T. Pentz, "Bacterial relationships in aquaponics: new research directions," in Aquaponics Food Production Systems, S. Goddek, A. Joyce, B. Kotzen, and G. M. Burnell, Eds., pp. 145-161, Springer, Cham, Switzerland, 2019.

[16] S. Wongkiew, M.-R. Park, K. Chandran, and S. K. Khanal, "Aquaponic systems for sustainable resource recovery: linking nitrogen transformations to microbial communities," Environmental Science \& Technology, vol. 52, no. 21, pp. 1272812739, 2018.

[17] M. Eck, A. R. Sare, S. Massart et al., "Exploring bacterial communities in aquaponic systems," Water, vol. 11, no. 2, p. 260, 2019.

[18] J. T. Lennon, "Replication lies and lesser-known truths regarding experimental design in environmental microbiology," Environmental Microbiology, vol. 13, no. 16, pp. 1383-1386, 2011.

[19] D. D. Myrold, L. H. Zeglin, and J. K. Jansson, "The potential of metagenomic approaches for understanding soil microbial processes," Soil Science Society of America Journal, vol. 78, no. 1, pp. 3-10, 2014. 
[20] P. D. Schloss, S. L. Westcott, T. Ryabin et al., "Introducing mothur: open-source, platform-independent, communitysupported software for describing and comparing microbial communities," Applied and Environmental Microbiology, vol. 75, no. 23, pp. 7537-7541, 2009.

[21] T. Rognes, T. Flouri, B. Nichols, C. Quince, and F. Mahé, "VSEARCH: a versatile open source tool for metagenomics," PeerJ, vol. 4, pp. 1-22, 2016.

[22] J. G. Holt, N. R. Krieg, P. H. A. Sneath, J. T. Staley, and S. T. Williams, Bergey's Manual of Determinative Bacteriology, Lippincott Williams and Wilkins. Co., Baltimore, MA, USA, 9th edition, 1994.

[23] M. Dworkin, S. Falkow, E. Rosenberg, K.-H. Schleifer, and E. Stackebrandt, "The prokaryotes," in A Handbook on the Biology of Bacteria, Springer, New York, NY, USA, 3rd edition, 2006.

[24] M. Ofek, Y. Hadar, and D. Minz, "Ecology of root colonizing Massilia (oxalobacteraceae)," PLoS One, vol. 7, no. 7, Article ID e40117, 2012.

[25] T. Coenye and P. Vandamme, "Diversity and significance of Burkholderia species occupying diverse ecological niches," Environmental Microbiology, vol. 5, no. 9, pp. 719-729, 2003.

[26] X. Li, J. Rui, Y. Mao, A. Yannarell, and R. Mackie, "Dynamics of the bacterial community structure in the rhizosphere of a maize cultivar," Soil Biology and Biochemistry, vol. 68, pp. 392-401, 2014.

[27] K. Busarakam, A. T. Bull, M. E. Trujillo et al., "Modestobacter caceresii sp. nov., novel actinobacteria with an insight into their adaptive mechanisms for survival in extreme hyper-arid atacama desert soils," Systematic and Applied Microbiology, vol. 39, no. 4, pp. 243-251, 2016.

[28] L. Xu, X. Zeng, Y. Nie et al., "Pontibacter diazotrophicus sp. nov., a novel nitrogen-fixing bacterium of the family cytophagaceae," PLoS One, vol. 9, no. 3, Article ID e92294, 2014.

[29] Z. Y. Wang, R. X. Wang, J. S. Zhou, J. F. Cheng, and Y. H. Li, "An assessment of the genomics, comparative genomics and cellulose degradation potential of Mucilaginibacter polytrichastri strain RG4-7," Bioresource Technology, vol. 297, pp. 1-11, 2020.

[30] R. Lopez-Mondejar, D. Zuehlke, D. Becher, K. Riedel, and P. Baldrian, "Cellulose and hemicellulose decomposition by forest soil bacteria proceeds by the action of structurally variable enzymatic systems," Scientific Reports, vol. 6, no. 25279, pp. 1-12, 2016.

[31] Z. Hu, J. W. Lee, K. Chandran, S. Kim, A. C. Brotto, and S. K. Khanal, "Effect of plant species on nitrogen recovery in aquaponics," Bioresource Technology, vol. 188, pp. 92-98, 2015.

[32] Y. Zou, Z. Hu, J. Zhang, H. Xie, C. Guimbaud, and Y. Fang, "Effects of $\mathrm{pH}$ on nitrogen transformations in media-based aquaponics," Bioresource Technology, vol. 210, pp. 81-87, 2016.

[33] M. Bomberg, J. Mäkinen, M. Salo, and P. Kinnunen, "High diversity in iron cycling microbial communities in acidic, iron-rich water of the Pyhäsalmi mine, Finland," Geofluids, vol. 2019, Article ID 7401304, 17 pages, 2019.

[34] N. Kasozi, R. Tandlich, M. Fick, H. Kaiser, and B. Wilhelmi, "Iron supplementation and management in aquaponic systems: a review," Aquaculture Reports, vol. 15, pp. 1-10, 2019.

[35] N. B. Svenningsen, S. J. Watts-Williams, E. J. Joner et al., "Suppression of the activity of arbuscular mycorrhizal fungi by the soil microbiota," The ISME Journal, vol. 12, no. 5, pp. 1296-1307, 2018.

[36] H. Kojima, R. Tokizawa, and M. Fukui, "Mizugakiibacter sediminis gen. nov., sp. nov., isolated from a freshwater lake,"
International Journal of Systematic and Evolutionary Microbiology, vol. 64, no. 12, pp. 3983-3987, 2014.

[37] M. Kolton, A. Erlacher, G. Berg, and E. Cytryn, "The Flavobacterium genus in the plant holobiont: ecological, physiological, and applicative insights," in Microbial Models: From Environmental to Industrial Sustainability. Microorganisms for Sustainability,S. Castro-Sowinski, Ed., vol. 1, pp. 189-207, Springer, Singapore, 2016.

[38] L. Guo, S. Zheng, C. Cao, and C. Li, "Tillage practices and straw-returning methods affect topsoil bacterial community and organic $\mathrm{C}$ under a rice-wheat cropping system in central China," Scientific Reports, vol. 6, no. 1, pp. 1-10, 2016.

[39] D. E. Koeck, A. Pechtl, V. V. Zverlov, and W. H. Schwarz, "Genomics of cellulolytic bacteria," Current Opinion in Biotechnology, vol. 29, pp. 171-183, 2014.

[40] J. Jezbera, J. Jezberová, U. Brandt, and M. W. Hahn, "Ubiquity of Polynucleobacter necessarius subspecies asymbioticus results from ecological diversification," Environmental Microbiology, vol. 13, no. 4, pp. 922-931, 2011.

[41] M. W. Hahn, T. Scheuerl, J. Jezberova et al., "The passive yet successful way of planktonic life: genomic and experimental analysis of the ecology of a free-living Polynucleobacter population," PLoS One, vol. 7, no. 3, Article ID e32772, 2012.

[42] A. K. Meneghine, S. Nielsen, A. M. Varani, T. Thomas, and L. M. C. Alves, "Metagenomic analysis of soil and freshwater from zoo agricultural area with organic fertilization," PLoS One, vol. 12, no. 12, Article ID e0190178, 2017.

[43] H. Y. Yildiz, L. Robaina, J. Pirhonen, E. Mente, D. Domínguez, and G. Parisi, "Fish welfare in aquaponic systems: its relation to water quality with an emphasis on feed and faeces-a review," Water, vol. 9, no. 13, pp. 2-17, 2017.

[44] A. K. Sharma, K. Sommerfeld, G. S. Bullerjahn et al., "Actinorhodopsin genes discovered in diverse freshwater habitats and among cultivated freshwater Actinobacteria," The ISME Journal, vol. 3, no. 6, pp. 726-737, 2009.

[45] R. Nakai, T. Fujisawa, Y. Nakamura et al., "Complete genome sequence of Aurantimicrobium minutum type strain $\mathrm{KNC}^{\mathrm{T}}$, a planktonic Ultramicrobacterium isolated from river water," Genome Announcements, vol. 4, no. 3, pp. 1-2, 2016.

[46] C. Wurzbacher, I. Salka, and H.-P. Grossart, "Environmental actinorhodopsin expression revealed by a newin situfiltration and fixation sampler," Environmental Microbiology Reports, vol. 4, no. 5, pp. 491-497, 2012.

[47] J. A. Peiffer, A. Spor, O. Koren et al., "Diversity and heritability of the maize rhizosphere microbiome under field conditions," Proceedings of the National Academy of Sciences, vol. 110, no. 16, pp. 6548-6553, 2013.

[48] G. R. Lewin, C. Carlos, M. G. Chevrette et al., "Evolution and ecology of Actinobacteria and their bioenergy applications," Annual Review of Microbiology, vol. 70, no. 1, pp. 235-254, 2016.

[49] E. A. Barka, P. Vatsa, L. Sanchez et al., "Taxonomy, physiology, and natural products of Actinobacteria," Microbiology and Molecular Biology Reviews, vol. 80, no. 1, pp. 1-43, 2016.

[50] S. D. Eisenlord and D. R. Zak, "Simulated atmospheric nitrogen deposition alters actinobacterial community composition in forest soils," Soil Science Society of America Journal, vol. 74, no. 4, pp. 1157-1166, 2010.

[51] B. Zhang, X. Wu, X. Tai et al., "Variation in actinobacterial community composition and potential function in different soil ecosystems belonging to the arid Heihe River Basin of Northwest China," Frontiers in Microbiology, vol. 10, pp. 1-11, Article ID 2209, 2019. 